\title{
On tidal stream turbines placed off headlands
}

Cite as: J. Renewable Sustainable Energy 7, 061706 (2015); https://doi.org/10.1063/1.4936361 Submitted: 30 June 2015 . Accepted: 09 November 2015. Published Online: 30 December 2015

T. A. A. Adcock (iD)
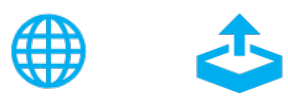

Export Citation

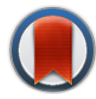

View Online

CrossMark

\section{ARTICLES YOU MAY BE INTERESTED IN}

Performance prediction of a tidal in-stream current energy converter and site assessment next to Jindo, South Korea

Journal of Renewable and Sustainable Energy 7, 061707 (2015); https://

doi.org/10.1063/1.4938027

\section{Preface to Special Topic: Marine Renewable Energy}

Journal of Renewable and Sustainable Energy 7, 061601 (2015); https://

doi.org/10.1063/1.4939086

Sea-state modification and heaving float interaction factors from physical modelling of arrays of wave energy converters

Journal of Renewable and Sustainable Energy 7, 061705 (2015); https://

doi.org/10.1063/1.4938030

\section{Sellight Highlights of the best new research} in the physical sciences 


\title{
On tidal stream turbines placed off headlands
}

\author{
T. A. A. Adcock \\ Department of Engineering Science, University of Oxford, Oxford OXI 3PJ, United Kingdom
}

(Received 30 June 2015; accepted 9 November 2015; published online 30 December 2015)

Many candidate sites for tidal stream energy extraction can be classified as headland sites. Understanding the tidal resource of such sites is of fundamental importance to the industry. This paper examines an upper bound for the power that might be generated from an idealised headland. The dependence of this on length of turbine rows, number of turbine rows, and turbine blockage ratio is examined. Conclusions are drawn from this which are applicable to real headland sites. (C) 2015 AIP Publishing LLC. [http://dx.doi.org/10.1063/1.4936361]

\section{INTRODUCTION}

Many candidate sites for tidal energy extraction may be classified as headland sites. Examples include St. David's Head, Anglesey, Portland Bill, and the Isle of Wight. To develop tidal turbine farms at these sites, it is important to be able to understand the characteristics of the tidal energy resource.

Currently, many different tidal stream devices are under development and the amount of energy a particular site can produce will be dependent on the actual type of turbine used. In this paper, we do not seek to examine the power a particular device will generate but instead examine the upper bound for the power which can be produced (see discussion in Ref. 1). An upper bound which has traditionally been used is the extractable energy of the site. However, a lower bound than this can be obtained by examining the power available for generation using actuator disc models to represent the inviscid limit on power generation by rows of tidal turbines. As more turbines are added the power per swept area of turbine falls until this drops below some cut off beyond which any extra power generation is unfeasible. For this paper, which considers an idealised problem, we just examine the general trends of how the power per swept area varies with turbine length and number of rows.

This paper analyses an idealised tidal headland using a depth-integrated numerical model. The objective of this work is to understand the general characteristics of a headland sites. Whilst all real locations will have slightly different characteristics, the aim of this paper is to establish some general, qualitative, trends which will be useful in analysing real locations. In particular, we look at how the available power varies with number of turbine rows, length of turbine rows, and the blockage ratio of the turbines (the fraction of the water column they take up (see, for instance, Ref. 2).

Draper $e t ~ a l .{ }^{3}$ analysed a similar idealised headland (although with a different geometry to the one in this study). Their study looked in detail at how tidal turbines modified the flow field around the headland and at the energy extraction. A number of other studies of headland sites appear in the literature. Blunden and Bahaj ${ }^{4}$ looked at how the flow varied around Portland Bill and where turbines should be located. Draper et al. ${ }^{5}$ conducted a physical experiment considering flow around a headland and compared experiments to a numerical model. The focus of this study was the comparison between the two modelling techniques rather than a fundamental look at flow around headlands. Serhadlığlu et al. ${ }^{6}$ considered the deployment of tidal turbines in the Anglesey Skerries. Her study considered some of the questions considered her but only analysed a few configurations, looking at whether turbines should be arranged in parallel or in series. Finally, Adcock and Draper ${ }^{7}$ considered tidal turbines places off the Isle of Wight and Portland Bill. The purpose of this study was to simplify the problem as far as possible, considering a flat bathymetry and removing as much of the site specific effects as possible, so as to 
try and improve our understanding of the key physics of tidal stream energy extraction from headlands.

\section{NUMERICAL MODEL}

\section{A. Numerical scheme}

The numerical model used in this paper is the discontinuous Galerkin (DG) version of ADCIRC. ${ }^{8,9}$ The model solves the shallow water equations which are typically used for tidal modelling. ${ }^{10}$ The numerical scheme has been verified and validated for various applications such as modelling tidal flows and storm surges.

In this study, we are modelling a headland site. The shallow water equations used here are known to give an imperfect model for the flow around islands ${ }^{11}$ and headlands. ${ }^{5}$ By its nature, a depth averaged model is unable to simulate features of realistic flows associated with curvature and vertical variations which are ignored in this study. This limitation also means we do not attempt to simulate the strongly three-dimensional wake of individual turbine but instead use a sub-grid scale model (see below) to describe these. Depth-averaged models will also struggle to model mixing between adjacent flows of differing velocity as this is usually, although not always, a three-dimensional process. This is a limitation to using depth-averaged models for simulating arrays of turbines. Nevertheless, the purpose of this study is to establish the leading order effects of placing rows of turbines off headlands and this hypothetical idealised flow provides a basis for qualitative analysis.

\section{B. Inclusion of tidal devices}

We represent tidal turbines in the model as a line discontinuity following the approach of Draper et al. ${ }^{12}$ This method imposes a change in the water level across the lines of turbines in the model. The change in water depth across the turbines is given by the finite Froude number actuator disc theory. ${ }^{13}$ The turbine characteristics are thus a function of upstream Froude number, $F r$ (non-dimensionalised flow speed), blockage ratio, $B$ (the proportion of the water column swept by turbines), and wake velocity coefficient, $\alpha_{4}$ (the velocity, relative to upstream of the flow which has passed through the turbines, at a distance downstream where local pressures have equalised). This model for the turbines gives both the "extracted power" and "available power." The extracted power is the power removed from the flow and is not considered in this paper. The available power is the extracted power minus the power lost in the inevitable mixing behind the turbines and thus constitutes an upper limit on the power which could be generated. Real turbines will, of course, not operate as efficiently as this and there will be additional losses due to the turbine support structure which are not considered in this paper.

The numerical implementation and verification of the sub-grid scale turbine model into the DG ADCIRC code is described in Ref. 14. In this implementation, the turbine properties $\left(\alpha_{4}\right.$ and $B$ ) are assigned to nodes. The edges where turbines are placed (and hence the Gaussian points within these elements) will take the average value of the turbine properties assigned to the nodes which define the edge. The tidal turbines blockage is based on the blockage at mean sea level-i.e., the area of the turbine remains the same causing a small change in blockage over the tidal cycle as the water level rises and falls. The model has been used to analyse tidal energy extraction from ocean basins. ${ }^{15}$

This model of turbine characteristics is not strictly valid at the seaward end of the fence where flow can bypass the turbine array creating a much more complex flow and mixing regime locally. In this study, we assume that any errors introduced by end effects will be negligible compared to the total power of the array, although this may be questionable for shorter arrays and hence we avoid analysing tidal turbine fences with lengths less than $500 \mathrm{~m}$. A detailed analysis of the different mixing scales is described in Ref. 16.

In this paper, we use the convention of describing the length of a row as extending to half way across the edge beyond the last node defined as containing turbine. Computationally, as described above, this edge will contain a turbine with a blockage half that of the rest of the array. 


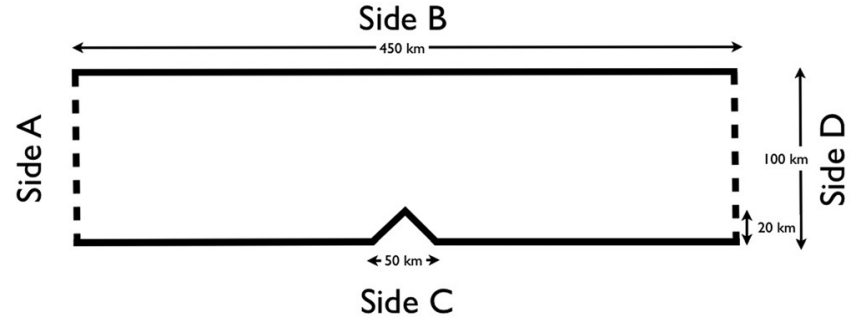

FIG. 1. Schematic of the domain used in this study. Land boundaries are shown with thick solid lines. Ocean boundaries are shown with thick dashed lines.

\section{Idealised domain}

In this study, we consider a headland in a wide channel as shown in Figure 1. The boundary $\mathrm{A}$ is forced with a tide of amplitude $2 \mathrm{~m}$ and period $12.42 \mathrm{~h}$. The water level on boundary $\mathrm{D}$ is held constant. The tidal amplitude at these boundaries is not altered when changes are made within the domain and thus could represent the boundary between a continental shelf and a very deep ocean. Boundaries B and C are land boundaries and are simulated as non-slip. The headland extends $20 \mathrm{~km}$ into the channel. The simulation is run on a Cartesian grid. Unlike the study of Draper et al., ${ }^{3}$ the headland we study has a constant water depth around the area of the headland of $15 \mathrm{~m}$. Whilst most physical headland sites do get deeper further from the shore, the slope is often rather shallow and so general results derived from a site with a flat bed are likely to be qualitatively applicable to most real sites. The domain is meshed as shown in Figures 2 and 3. The mesh is mainly unstructured except for two rows at the end of the headland where turbines are placed. The model uses a bed friction coefficient of 0.0025 which is in the range typically applied to tidal models. ${ }^{17}$

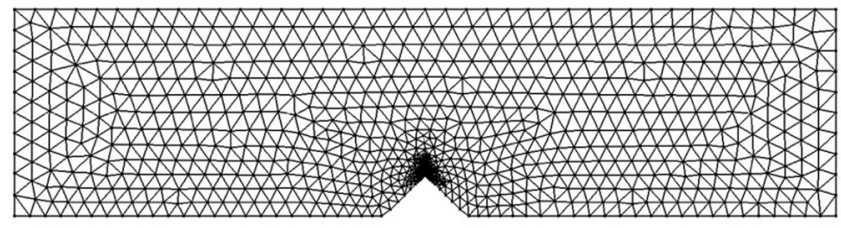

FIG. 2. Numerical mesh used in study.

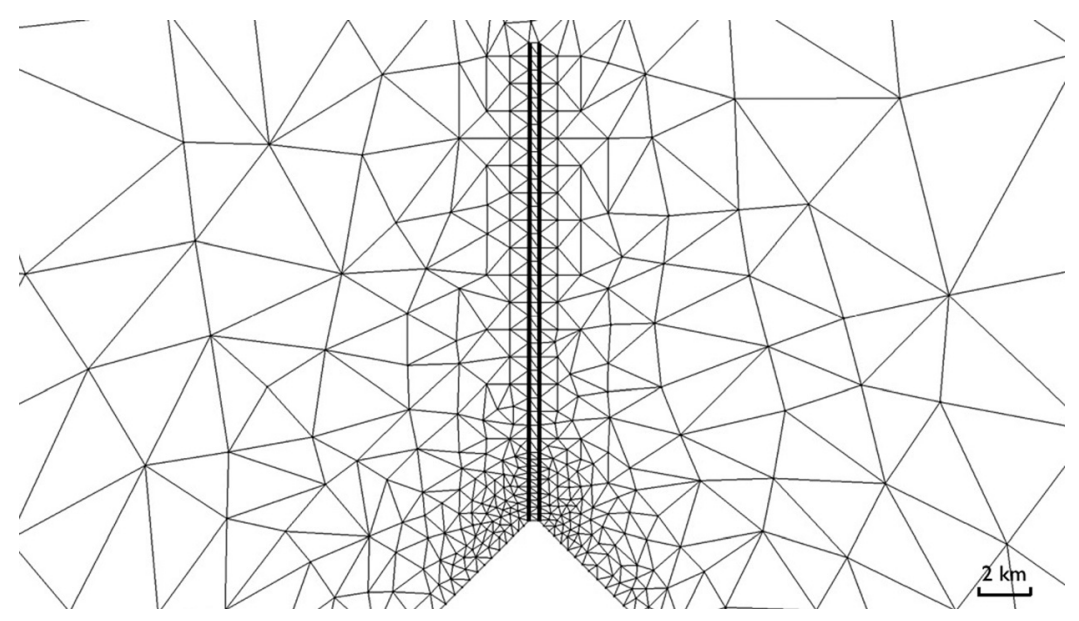

FIG. 3. Close up of numerical mesh around headland. Turbines are shown with thick black lines. 


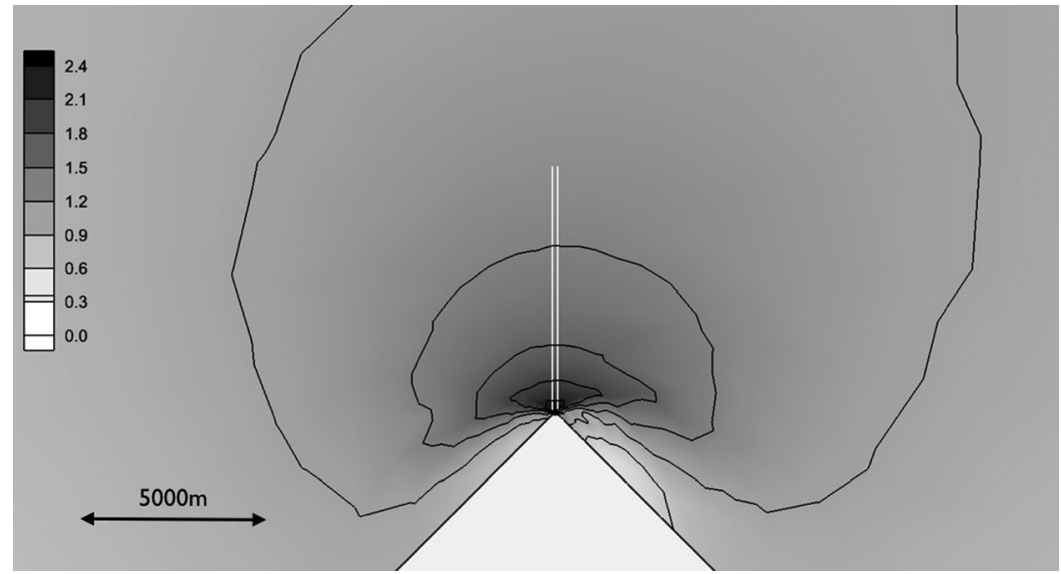

FIG. 4. $M_{2}$ current magnitude $(\mathrm{m} / \mathrm{s})$ in the absence of tidal turbine. Turbine locations shown with white lines.

\section{UNDISTURBED FLOW CHARACTERISTICS}

The model was allowed to "spin up" for one day before starting the analysis. The model produces a fast flowing current around the tip of the headland, and separation occurs behind the headland. There is no vortex shedding or similar structures which detach from the headland. The flow is not symmetric - there is a stronger current moving left-to-right than right-to-left. Fig. 4 shows the magnitude of the $M_{2}$ tidal component.

To give more details, the flow snapshots of the flow at peak current in each direction are presented in Figure 5. The separation off the tip of the headland is shown with subtle differences between the flows when it is going from left to right compared with the flows from right to left.

Draper et $a l .{ }^{3}$ have demonstrated that the natural kinetic energy flux does not determine the total resource of a site and is neither an upper nor a lower bound to this. Despite this, kinetic

(a)

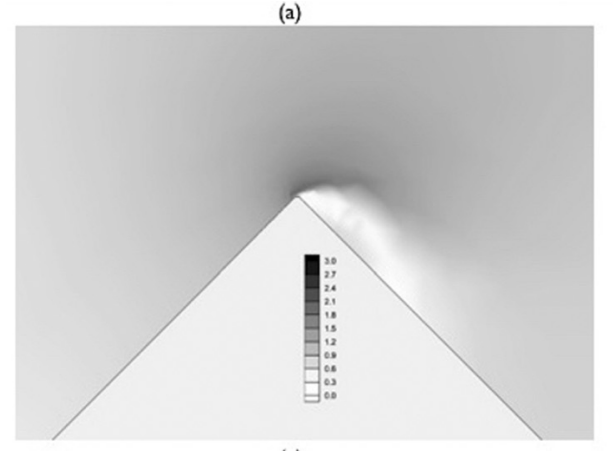

(c)

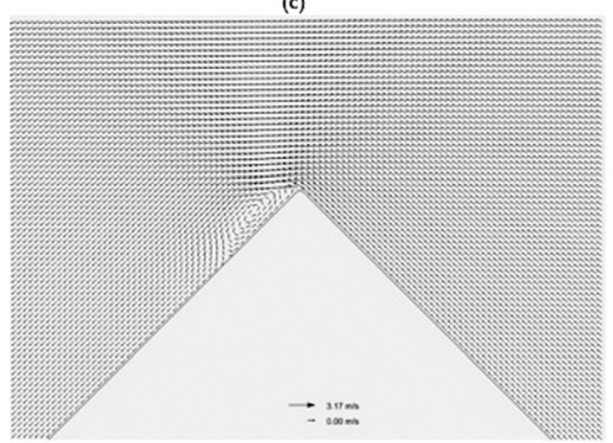

(b)

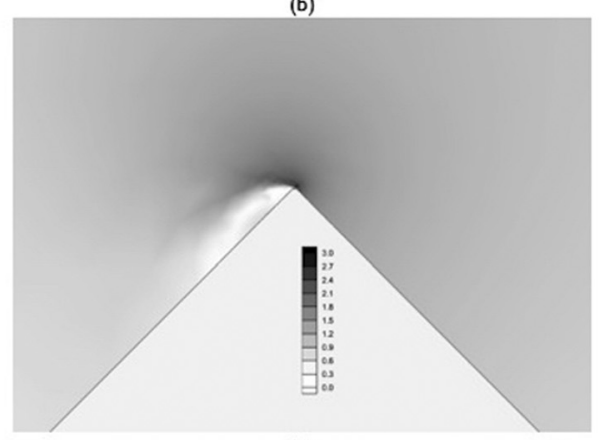

(d)

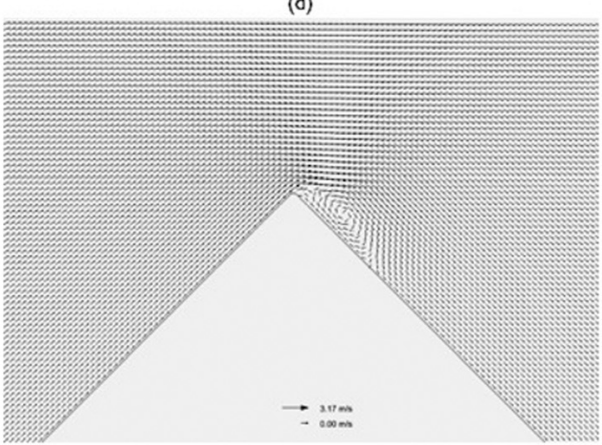

FIG. 5. Examples of flows in the absence of turbines. (a) Flow magnitude with flow moving left to right. (b) Flow magnitude with flow moving right to left. (c) Flow direction with flow moving right to left. (d) Flow direction with flow moving left to right. 
energy flux is a useful metric for understanding a $\operatorname{sit}^{18}$ and has been widely used in the past. Figure 6 shows the sum of the kinetic energy passing between the tip of the headland and a point directly offshore of it. The kinetic energy flux is strongest closest to the headland and reduces further offshore. For example, the kinetic energy flux between a point $1200 \mathrm{~m}$ from the headland and the tip of the headland is approximately the same as between $1200 \mathrm{~m}$ from the headland and $7000 \mathrm{~m}$.

\section{OPTIMAL DISTRIBUTION OF TURBINE PARAMETERS}

If the current is unaffected by the tidal turbines then the best performing turbine, in terms of available power, will have a wake velocity coefficient, $\alpha_{4}=0.33$ (for $\alpha_{4}$ notation see Ref. 13). In real tidal flows, there will be a reduction in the flow due to the presence of the turbine and in this case a larger $\alpha_{4}$ (implying a smaller drag and therefore less reduction in current) may give a greater available power. ${ }^{19}$

To find the turbine characteristics that maximise the available energy, we have to run a series of simulations with different turbine properties and analyse these to find the optimum. However, the value of $\alpha_{4}$ which maximises energy extraction will vary across the width of a turbine fence as different parts of the fence experience currents of differing magnitude.

In this paper, we approximate the optimum distribution of $\alpha_{4}$ along a turbine fence as being linear and define this using the values at each end of the array. The true optimal layout is unknown. We have considered more complicated functions which do yield small increases in available power (a few percent) and of course the true optimum will be still higher. However, to search for this optimum for all cases would require an unfeasible computational effort. However all the results presented in this paper will underestimate the true maximum available power but this effect is too small to alter the conclusions drawn from this work.

Figure 7 shows how the dependence of available power on the wake velocity coefficient for a range of turbine lengths where the blockage ratio is 0.5 . These show that even for this very high blockage, the peak available power is relatively insensitive to the exact values of $\alpha_{4}$. We can also see that the benefit of varying the wake velocity coefficient across the length of the turbine is typically relatively small $(\sim 5 \%)$. Such a small improvement in available power implies that a reasonable estimate of the available power for a site might be obtained without considering the variation in turbine properties across the site. However, in real sites the flow profile will be more complex than the one we are considering here so it is clearly desirable that a study such as this should be undertaken in the analysis of real locations.

This study indicates that it is preferable to have turbines operating with a lower wake velocity coefficient at the seaward end of a turbine row than at the land end.

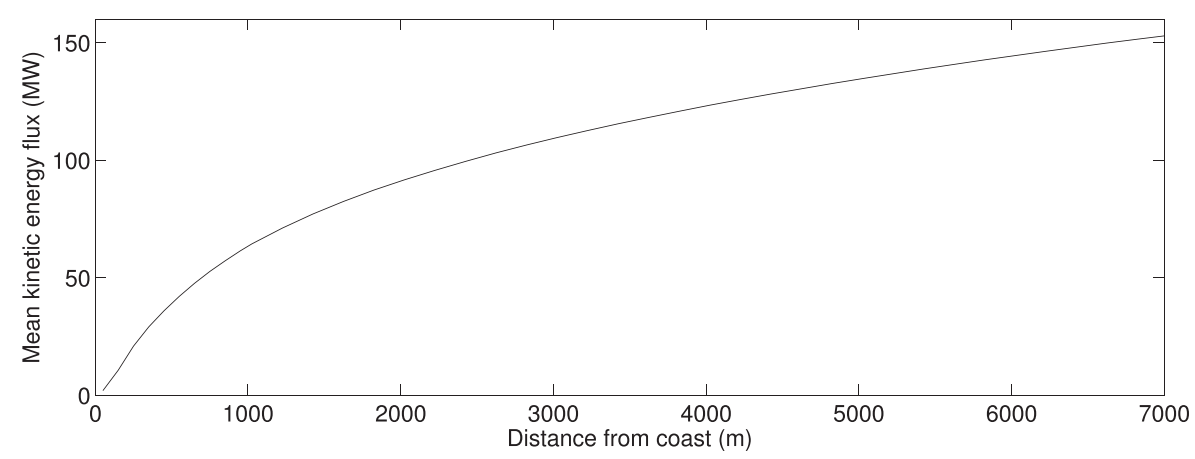

FIG. 6. Sum of the kinetic energy flux passing between the headland and a point located a distance offshore from the headland. 

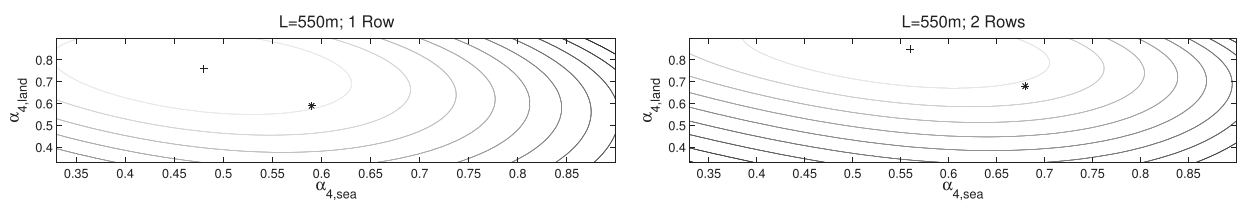

L=950m; 1 Row

L=950m; 2 Rows
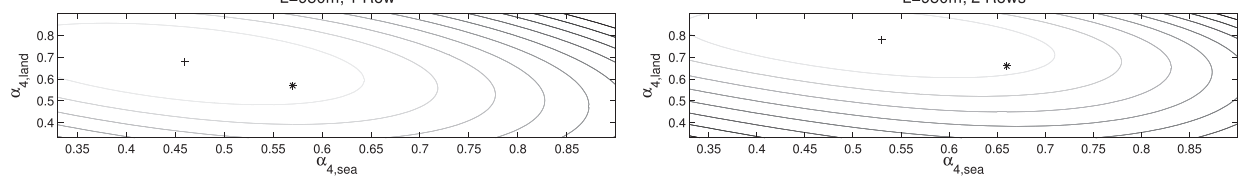

$\mathrm{L}=1800 \mathrm{~m} ; 1$ Row

$\mathrm{L}=1800 \mathrm{~m} ; 2$ Rows
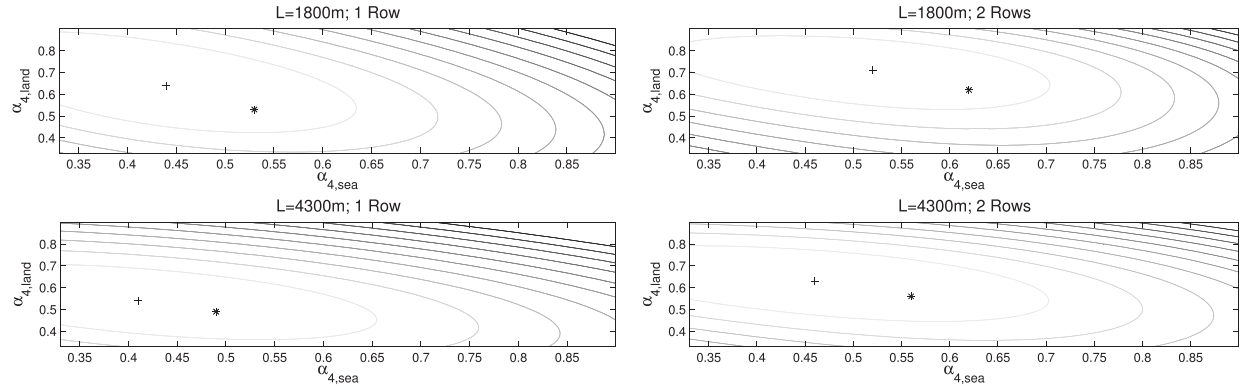

FIG. 7. Available power for different wake velocity coefficients. Contours are available power normalised by maximum available power and are in gaps of 0.05 between 0.5 and $f$ with 0.5 the darkest. The optimum location for a linear variation in $\alpha_{4}$ is shown with a plus; the optimum location for a constant $\alpha_{4}$ is shown with an asterisk.

We note that it might that a further improvement in the turbine performance may perhaps be achieved by varying the temporal properties of the turbines either over a short timescale ${ }^{20,21}$ or over the longer spring/neap cycle. ${ }^{22}$ These are not considered further here.

\section{RESULTS}

In this section, we investigate how the available power varies with the length and number of turbine fences. Two blockage ratios are considered: a "high" blockage ratio of 0.5 and a
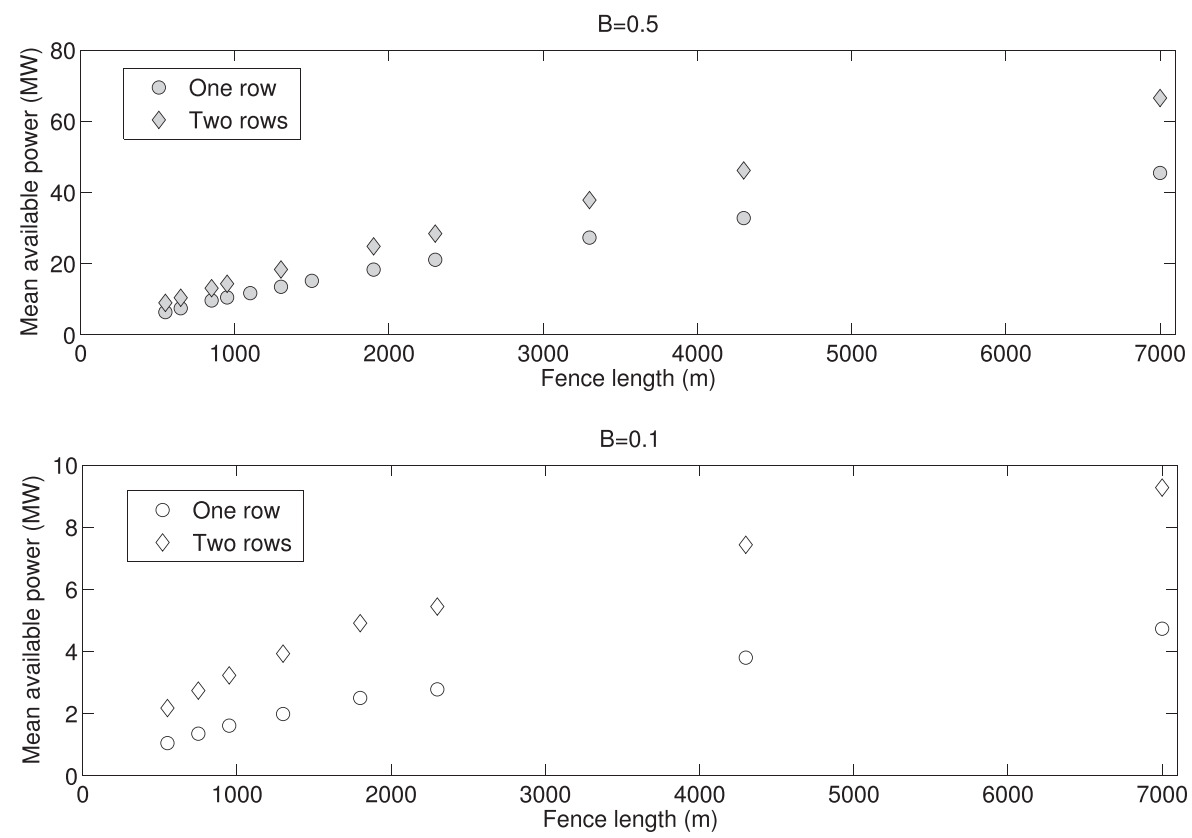

FIG. 8. Available power for different lengths of turbine fence and different blockage ratios. Circles denote one row of turbines; diamonds denotes two rows. 
"small" blockage ratio of 0.1 . The object of this is to show the different trends for two extremes of blockages.

Figure 8 shows how the available power varies with length of turbine fence. In all cases, the available power increases as turbine rows are made longer and as additional rows are deployed. These curves may be compared to the naturally occurring kinetic energy flux (Figure 6). In all cases considered here the available power is less than the naturally occurring kinetic energy flux. For low blockage cases, there is little change to the flow and the graph of available power is close in shape to that of kinetic energy flux. However, for higher blockages the curve is rather flatter. For instance, for two rows of high blockage turbines of length $\sim 1200 \mathrm{~m}$ will have an available power of less than a third of two rows of turbines $\sim 7000 \mathrm{~m}$, whereas a prediction based on naturally occurring kinetic energy flux would be that the $\sim 1200 \mathrm{~m}$ turbines would have half the power of turbines extending $\sim 7000 \mathrm{~m}$.

Figure 9 shows how the power per swept area varies for one and two rows of turbines. For each specified number of rows and blockage ratio, there is a decrease in the power per swept area as the total area increases. This is expected as the increased area is obtained by extending the turbine rows further offshore into where the naturally occurring current is weaker. There is a slightly different trend for short rows of highly blocked turbines. This is possibly due to the longer rows preventing flow from diverting around the turbines. It is plausible that in a different geometry there might even be a peak in this curve.

There is a significant difference between the trends for high local blockage and low local blockage as additional rows are added. For highly blocked turbines, for a given total area of turbine and local blockage, it is always advantageous to arrange them as a single line rather than in rows close to the headland. Conversely, for the low blockage case, for a given total swept area, the maximum available power is achieved by deploying two rows of half the length.

This can be explored further by studying additional rows of low blockage turbines. Rather than including additional rows directly in the model, we use the approximate method described in Ref. 3. This method is based on using an equivalent head loss, over two rows in this case, to represent the head loss over multiple rows. The available power can then be found from the efficiency of the turbine given in Ref. 13. Figure 10 explores the effect of adding multiple rows of low blockage turbines for three different row lengths. With the exception of moving from one to two rows (presumably due to local effects), there is a steady decrease in the power per

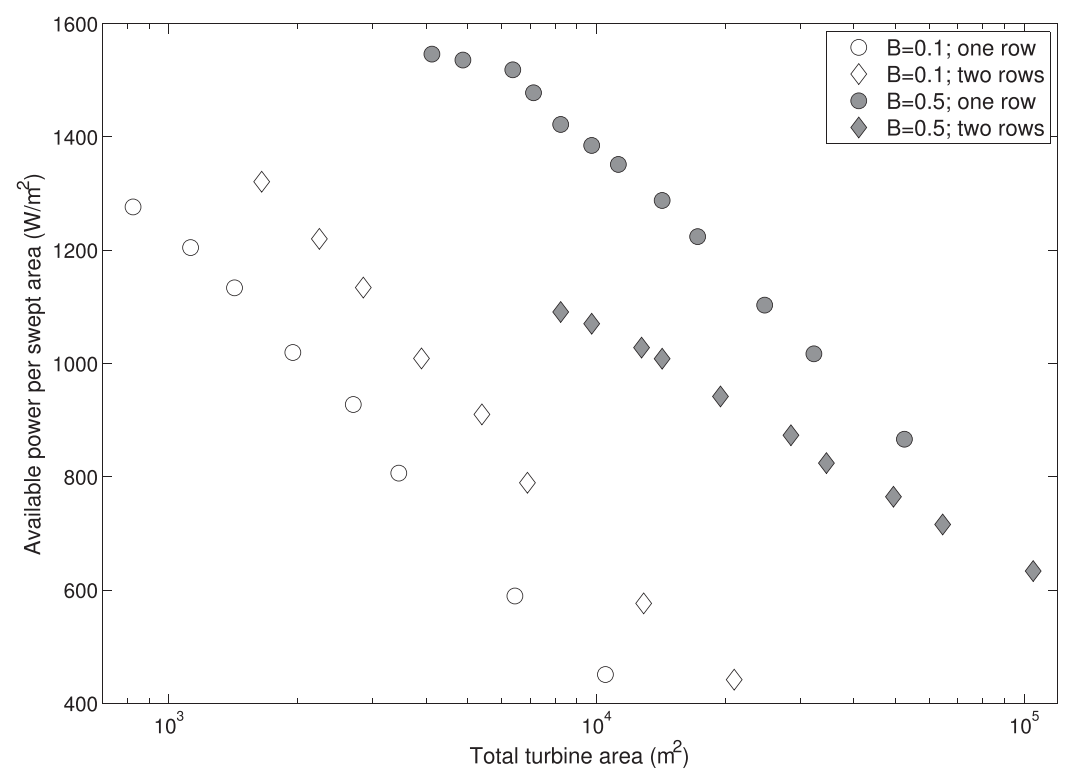

FIG. 9. The available power per swept area against the total area of turbines deployed. Grey symbols show $B=0.5$ and white symbols $B=0.1$. Circles indicate one row of turbines and diamonds two rows. 


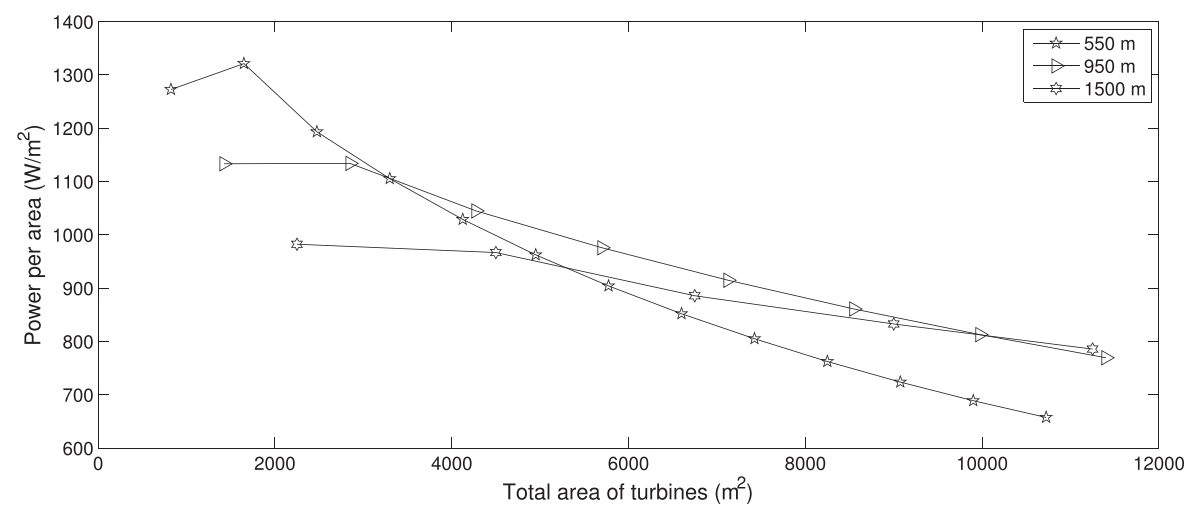

FIG. 10. The power per swept area for different numbers of rows of turbines with blockage 0.1. For turbine rows of $550 \mathrm{~m}$ results from thirteen rows are shown; for turbine rows $950 \mathrm{~m}$ results from eight rows are shown; for turbine rows $1500 \mathrm{~m}$ results from five rows are shown.

area as a greater total area of turbines are deployed. For a given total turbine area, it is of interest to know configuration which gives the optimum available power. When only a small swept area of turbines is considered, it is preferable to exploit the strongest currents close to the headland. Adding more rows allows the turbines to apply a greater total thrust to the flow and for each row to be operated more efficiently (i.e., higher $\alpha_{4}$ ). However, there is a diminishing return of available power as additional rows are added and so there is a limit where instead of adding extra rows, it is preferable to increase the length of the rows. For example, considered in this paper this limit appears to be around two rows for the low blockage case, and a single row when high blockage is used. Thus it appears preferable to use longer rows of turbines extending into areas, where the naturally occurring flow is weaker, than to use many short turbine fences close to the headland where the natural flow is stronger. Extracting energy from a tidal current requires a thrust to be applied to the flow. This causes a change in the flow around the headland. Figure 11 examines the change in the $M_{2}$ tidal component for different lengths of turbine row, at peak available energy extraction for one row of highly blocked turbines. At peak available power, there is a considerable reduction in the flow through the area where turbines are deployed. There is also an increase in the flow passing offshore of the turbines. The presence of turbines is evidently causing the flow to be diverted around the end of the turbines. The magnitude of the diversion is obviously related to the thrust the turbines exert on the flow. Thus, the metric of basin efficiency (the ratio of useful energy to energy extracted from the flow) will be relatively more important for turbines placed at headland sites than the turbines placed in channels where no flow diversion is possible.

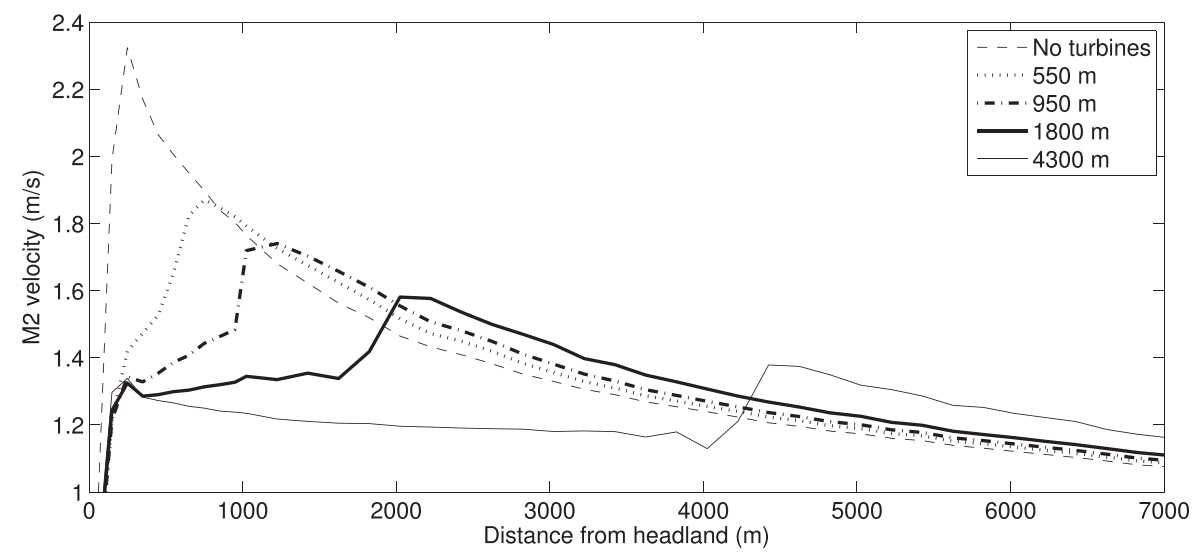

FIG. 11. Magnitude of M2 tidal current component at peak available energy extraction. For one row of turbines with $\mathrm{B}=0.5$. 


\section{CONCLUSIONS}

This study has analysed an idealised headland in a channel with the aim of drawing some general conclusions regarding the resource assessment and design of tidal farms at headland sites. A depth-integrated numerical model of a headland has been set-up and actuator disc theory used to model the effect of tidal turbines within the model. A high and a low blockage ratio are considered.

We find that it is always hydrodynamically favourable to use the higher blockage ratio as this can extract energy with lower mixing losses than the low blockage turbines. As more rows of turbines are added, there is a diminishing return and, in general, it is advantageous to extend one or two rows of turbines further from the headland than to install multiple rows close to the headland.

${ }^{1}$ T. A. A. Adcock, S. Draper, and T. Nishino, "Tidal power generation-A review of hydrodynamic modelling," Proc. Inst. Mech. Eng., Part A 229(7), 755-771 (2015).

${ }^{2}$ C. Garrett and P. Cummins, "The efficiency of a turbine in a tidal channel," J. Fluid Mech. 588, 243-251 (2007).

${ }^{3}$ S. Draper, A. G. L. Borthwick, and G. T. Houlsby, "Energy potential of a tidal fence deployed near a coastal headland," Philos. Trans. R. Soc., A 371(1985), 20120176 (2013).

${ }^{4}$ L. S. Blunden and A. S. Bahaj, "Initial evaluation of tidal stream energy resources at Portland Bill, UK," Renewable Energy 31(2), 121-132 (2006).

${ }^{5}$ S. Draper, T. Stallard, P. Stansby, S. Way, and T. Adcock, "Laboratory scale experiments and preliminary modelling to investigate basin scale tidal stream energy extraction," in 10th European Wave and Tidal Energy Conference (EWTEC), Aalborg, Denmark, 2013.

${ }^{6}$ S. Serhadlığlu, T. A. A. Adcock, G. T. Houlsby, S. Draper, and A. G. L. Borthwick, "Tidal stream energy resource assessment of the Anglesey Skerries," Int. J. Mar. Energy 3, e98-e111 (2013).

${ }^{7}$ T. A. A. Adcock and S. Draper, "On the tidal stream resource of two headland sites in the English Channel: Portland Bill and Isle of Wight," in 33rd International Conference on Ocean, Offshore and Arctic Engineering, American Society of Mechanical Engineers, 2014, p. V09AT09A003.

${ }^{8}$ E. J. Kubatko, J. J. Westerink, and C. Dawson, "HP discontinuous Galerkin methods for advection dominated problems in shallow water flow," Comput. Methods Appl. Mech. Eng. 196(1), 437-451 (2006).

${ }^{9}$ E. J. Kubatko, S. Bunya, C. Dawson, J. J. Westerink, and C. Mirabito, "A performance comparison of continuous and discontinuous finite element shallow water models," J. Sci. Comput. 40(1-3), 315-339 (2009).

${ }^{10}$ R. A. Falconer, An Introduction to Nearly Horizontal Flows, Coastal, Estuarial and Harbour Engineers Reference Book (E \& FN Spon Ltd., London, 1993).

${ }^{11}$ P. K. Stansby, "Limitations of depth-averaged modeling for shallow wakes," J. Hydraul. Eng. 132(7), 737-740 (2006).

${ }^{12}$ S. Draper, G. T. Houlsby, M. L. G. Oldfleld, and A. G. L. Borthwick, "Modelling tidal energy extraction in a depthaveraged coastal domain,” IET Renewable Power Gener. 4(6), 545-554 (2010).

${ }^{13}$ G. T. Houlsby, S. Draper, and M. L. G. Oldfield, "Application of linear momentum actuator disc theory to open channel flow," Technical Report No. 08, University of Oxford, 2008.

${ }^{14}$ S. Serhadlığlu, "Tidal stream resource assessment of the Anglesey Skerries and the Bristol Channel," DPhil. thesis, University of Oxford, 2014.

${ }^{15}$ T. A. A. Adcock, S. Draper, G. T. Houlsby, A. G. L. Borthwick, and S. Serhadlıoğlu, "The available power from tidal stream turbines in the Pentland Firth,” Proc. R. Soc. London, Ser. A 469(2157), 20130072 (2013).

${ }^{16}$ T. Nishino and R. H. J. Willden, "The efficiency of an array of tidal turbines partially blocking a wide channel," J. Fluid Mech. 708, 596 (2012)

${ }^{17}$ R. Soulsby, Dynamics of Marine Sands: A Manual for Practical Applications (Thomas Telford, 1997).

${ }^{18}$ T. A. A. Adcock and S. Draper, "Different metrics for the analysis of candidate sites for tidal stream energy," in 1 st PRIMARE Annual Conference, 4-5 June 2014, Plymouth, UK.

${ }^{19}$ R. Vennell, “Tuning turbines in a tidal channel,” J. Fluid Mech. 663, 253-267 (2010).

${ }^{20}$ T. A. A. Adcock, "On the Garrett and Cummins limit," in Proceedings of the Oxford Tidal Energy Workshop, 2012.

${ }^{21}$ R. Vennell and T. A. A. Adcock, "Energy storage inherent in large tidal turbine farms," Proc. R. Soc. London, Ser. A 470(2166), 20130580 (2014).

${ }^{22}$ T. A. A. Adcock and S. Draper, "Power extraction from tidal channels-Multiple tidal constituents, compound tides and overtides," Renewable Energy 63, 797-806 (2014). 